\title{
Spatial structure of the Kodar-Kalar orobiome botanical diversity on bioclimatic basis
}

\author{
Maxim V. Bocharnikov ${ }^{1, *}$, and Anton A. Stas'ko ${ }^{1}$ \\ ${ }^{1}$ M.V. Lomonosov Moscow State University, 119991, Leninskie gory, 1, Moscow, Russia
}

\begin{abstract}
Bioclimatic substantiation of the vegetation spatial structure of the Kodar-Kalar orobiome on the basis of altitudinal vegetation divisions using the global climate model (BioClim) was carried out. Statistical analysis showed differences between altitudinal belts, sub-belts and also larch forests types on average annual temperature and average annual precipitation. The possibility of using the climate as a factor of differentiation of the vegetation cover at the regional level has been proved.
\end{abstract}

\section{Introduction}

The estimation of botanical diversity is necessary for its comparative geographical analysis, monitoring and development of environmental measures. The use the botanicalgeographical units as a basis has advantages in diversity evaluation. The concept of biome diversity (the hierarchical structure was created by Walter and Brackle [1]) considers biomes as the basic regional unit for assessing biodiversity. It has the most optimal relationships with the abiotic environment, primarily with climatic conditions and landscape structure of the territory. Development of the concept has found on the map "Biomes of Russia" [2].

The biome concept allows estimating the biodiversity of heterogeneous in its spatial structure mountain areas on the basis of a complete altitudinal spectrum of vegetation. Each spectrum has a regional specificity expressed in types and groups of types of altitudinal zonality. In the mountains with altitudinal patterns of the vegetation cover structure and their integral expression in the types of vegetation belts at the regional level, the organization of the biota is distinguished by orobiomes. The spatial structure of the orobiome vegetation cover is reflected at different levels of the biota organization. The unity of orobiomes is based on the diversity of a complete altitudinal spectrum of vegetation in certain geographical conditions.

Orobiomes of regional level have a number of key criteria and indicators of biota and abiotic conditions. The specificity of orobiomes characterizes their biogeographic integrity as a combination of natural ecosystems developing under the influence of altitudinal regularities. These include the following: a complex of abiotic factors (primarily bioclimatic, geological, geomorphological, landscape) and the character of the altitudinal gradient of their quantitative indices; the level of floristic diversity (total species richness,

\footnotetext{
*Corresponding author: maxim-msu-bg@mail.ru
} 
number of species per unit area) and the gradient of its variation along the altitudinal spectrum; the level of cenotic diversity (the number of basic and unique plant communities of altitudinal belt units); development of florocenogenetic complexes and their role in the vegetation cover; spatial patterns in altitudinal organization of the vegetation cover in connection with the specificity of prevailing processes. The main purpose of this investigation is evaluation of climatic factor in spatial structure of vegetation cover based on bioclimatic parameters.

\section{Materials and methods}

Selected criteria at the regional level should be used integrally for the whole orobiome. Bioclimatic characteristics have been selected as the main in the analysis of the KodarKalar orobiome (the Northern Transbaikalia area). The general patterns of its structure in mountain conditions are reflected in the typology of altitudinal zonality [3] and in the level of biodiversity. The regional specifics are defined by the biome organization. Botanicalgeographical mapping made a special contribution to revealing the structure of orobiome vegetation cover by the basis of altitudinal spectrum.

Information about the spatial structure of the Kodar-Kalar orobiome vegetation cover was taken from the vegetation map of the south of Eastern Siberia (s. 1: 1500 000) [4]. Typological units related to the East Siberian mountain tundra, Altai-Tien-Shan alpine, Ural-South Siberian, Angarida and Beringia boreal complexes of plant communities were reflected in its legend in according to the geographic-genetic classification [5].

The global digital model BioClim (Hijmans et al., 2005) was taken as the climatic data. Raster layers (spatial resolution - 30 arc seconds) with continuous values of temperature and moisture supply parameters were used: the average annual temperature, the average summer temperature (warm quarter of the year), the average winter temperature (cold quarter of the year), the temperature amplitude (the difference between the maximum temperature of the warmest and lowest temperatures of the coldest months), the average annual precipitation, the average summer precipitation (warm quarter of the year), the amount of precipitation for the winter (the cold quarter of the year).

A quantitative interpretation of the regularities of vegetation distribution in connection with climatic conditions was carried out on the basis of a comparison of raster layers with climatic layers of BioClim. Altitudinal vegetation belts and types of larch (Larix gmelinii (Rupr.) Rupr.) forests as the key subdivisions of the mountain taiga belt were used in analysis. The main descriptive statistics for each of the typological subdivisions by the set of pixels were determined based on the spatial resolution of the climatic model: maximum and minimum values, arithmetic mean, its error and standard deviation from the mean. The veracity of the differences between the levels of temperature and moisture availability of vegetation of different altitudinal divisions and types of larch forests was estimated using Student's t-test.

\section{Results}

The parameters of the average annual temperature and the average annual precipitation diagnose altitudinal vegetation subdivisions for orobiome, changing proportionally to their position in the altitude spectrum (Table 1). The mountain taiga belt of larch forests is developed at the average annual temperatures from $-5^{\circ}$ to $-10^{\circ} \mathrm{C}$. Pine forests grow with the greatest temperature supply. In the interval of the average annual temperatures from $-8^{\circ}$ to $-10^{\circ} \mathrm{C}$ the sub-tundra belt change the mountain taiga belt. In a wide range of temperatures $\left(-9^{\circ}-13^{\circ} \mathrm{C}\right)$ the vegetation cover of the mountain tundra and the upper tundra 
belts is formed. The amplitude of mean annual precipitation over altitudinal gradient is small. The lower sub-belt of the mountain taiga belt has the least moisture (about $400 \mathrm{~mm}$ of precipitation a year or less). It is associated with intermountain depressions with increased continental climate. Highlands have the highest moisture content (more than 500 $\mathrm{mm}$ of precipitation a year). In the warm period of the year, the increase in the amount of precipitation corresponds to the change of belts along the spectrum from the lower to the higher. In the cold period of the year, the dependence is nonlinear - the greatest amount of precipitation falls on the Siberian dwarf pine sub-belt and decreases up and down along the altitudinal spectrum.

Table 1. Bioclimatic indicators of the altitudinal vegetation belts and sub-belts of the Kodar-Kalar orobiome vegetation cover.

\begin{tabular}{|c|c|c|c|c|c|c|}
\hline \multicolumn{2}{|c|}{$\begin{array}{l}\text { The altitudinal belts and } \\
\text { sub-belts }\end{array}$} & I, II & III.1 & III. 2 & IV.1 & IV.2 \\
\hline \multicolumn{2}{|c|}{ Number of pixels } & 13135 & 13953 & 11256 & 45173 & 2642 \\
\hline \multicolumn{2}{|c|}{ Area, \% } & 15 & 16 & 13 & 53 & 3 \\
\hline \multirow{4}{*}{ 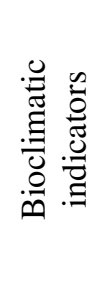 } & Tyear & $-10.9 \pm 2$ & $-9.9 \pm 1.9$ & $-9.4 \pm 1.5$ & $-8.3 \pm 1.5$ & $-6.9 \pm 1.7$ \\
\hline & Tmax_year & $9.7 \pm 1.9$ & $10.9 \pm 1.9$ & $11.6 \pm 1.3$ & $12.6 \pm 1.7$ & $13.9 \pm 1.7$ \\
\hline & Prec_year & $490 \pm 48$ & $469 \pm 50$ & $467 \pm 42$ & $437 \pm 49$ & $391 \pm 44$ \\
\hline & $\underset{r}{P r e c \_m a x \_y e a ~}$ & $286 \pm 32$ & $264 \pm 37$ & $246 \pm 26$ & $235 \pm 33$ & $215 \pm 37$ \\
\hline
\end{tabular}

The altitudinal belts and sub-belts: I - the upper tundra belt; II - the tundra belt; III - the sub-tundra belt: III.1 - the Siberian dwarf pine sub-belt, III.2 - the sparse forests sub-belt; IV - the mountain taiga belt: IV.1 - the larch forests sub-belt, IV.2 - the larch-pine and fir-pine-spruce forests sub-belt. The bioclimatic parameters (mean \pm STD): mean annual temperature (Tyear); the average temperature of the warmest quarter of the year (Tmax_year); the average annual precipitation (Prec_year), the sum of the precipitation of the warmest quarter of the year (Prec_max_year).

The bioclimatic indicators are chosen also for estimation of spatial structure of larch forests types. The average annual temperature and the average annual precipitation are considered as the key bioclimatic indicators.

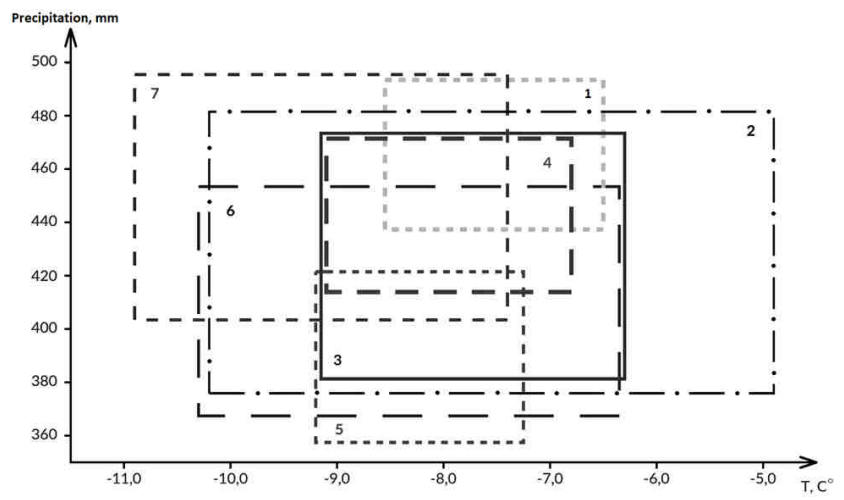

Fig. 1. Ordination of larch forests types according to the average annual temperature $\left(T, C^{\circ}\right)$ and annual precipitation (prec., mm).Larch forests types: 1 - Rhododendron aureum; 2 -Rhododendron 
dauricum; 3 - Vaccinium vitis-idaea; 4 - Duschekia fruticosa; 5 - Vaccinium uliginosum and Ledum palustre; 6 - Betula divaricata and B. exilis; 7 - Pinus pumila.

\section{Discussion}

The altitudinal structure of Kodar-Kalar orobiome vegetation cover conform to the main bioclimatic gradients. Such patterns has been showed for vegetation belts and also typological units of forest vegetation [7, 8]. In this paper, the climatic conditions analysis of larch forests for the Kodar-Kalar orobiome (Angarida complex communities) as the basic vegetation for mountain taiga belt has been showed. They are formed in a wide range of conditions - from temperate cold and temperate humid $\left(\Sigma \mathrm{T}>10^{\circ} \mathrm{C}-1000-1400^{\circ} \mathrm{C}\right)$ with sparse larch forests on the boundary of the mountain taiga and sub-tundra belts to temperate warm and temperate humid (average annual precipitation is less than $400 \mathrm{~mm}$ ) with communities in the Upper Angara and Muya-Kuanda depressions, where larch forests grow together with pine forests. A certain climatic range of larch forests of the orobiome in comparison with the larch (Larix sibirica Ledeb.) forests [6] is located in the range of same values of temperature supply, but with lower amount of precipitation (in mountains of Southern Siberia they grow at $\Sigma \mathrm{T}>10^{\circ} \mathrm{C}$ to $1500^{\circ} \mathrm{C}$ and average annual precipitation to $600 \mathrm{~mm})$.

Rhododendron (Rhododendron aureum Georgi) larch forests are common in the west and north-west parts of the orobiome, occupying the windward macro-slopes of the North Baikal and the Patom highlands. This explains the maximum annual precipitation among the larch forests types $(460 \mathrm{~mm})$. Rhododendron larch forests occupy a sufficiently high position in the altitudinal belt $(700-900 \mathrm{~m})$. The average annual temperature value of these forests does not drop below $-7^{\circ} \mathrm{C}$, which is the largest value among other types.

According to indication of climatic factor for units of phytosociological classification of Siberian and Far East vegetation, the larch forests are characterized by maximum continentality [9]. It is confirmed by the low values of the average annual temperature. In the first time the different amplitudes of temperature and moisture supply has been received and explained through altitudinal and geographic patterns for different types of larch forests based on geographic-genetic classification.

This research was supported by the grant of Russian Science Foundation (project № 17-77-10142).

\section{References}

1. H. Walter, S.-W. Breckle, Okologishe Grundlagen in global sicht (G. Fischer, Stuttgart, 1991)

2. Map "Biomes of Russia" (S. 1: 7500 000) in a series of nature maps for higher education. Ed. G. N. Ogureeva (Financial and Organizational Consulting LLC, Moscow, 2015)

3. G.N. Ogureeva, M.V. Bocharnikov, Ecos.: Ecol. and Dyn. 1, 52-81 (2017)

4. A.V. Belov, Geobot. Map. (Leningrad, 1973)

5. V.B. Sochava, Geographical aspects of the Siberian taiga (Nauka, Novosibirsk, 1980)

6. N.P. Polikarpov, N. M. Chebakova, D. I. Nazimova, Climate and mountain forests of Southern Siberia (Nauka, Novosibirsk, 1986)

7. E.O. Box, Vegetation Science in Forestry (Kluw. Acad. Publ., Dordtrecht, 1995)

8. S. Rivas-Martinez, D. Sanchez-Mata, M. Costa, Itin. Geobot. 12, (1999)

9. Y. Nakamura, P.V. Krestov, A.M. Omelko, Phytocoen 37, 433-470 (2007) 